\title{
Depletion of B Lymphocytes in Idiopathic Membranous Glomerulopathy: Results from Patients with Extended Follow-Up
}

\author{
Sophia Lionaki ${ }^{a}$ Smaragdi Marinaki $^{a} \quad$ Lydia Nakopoulou $^{b}$ \\ Chrysanthi Skalioti $^{a}$ Aliki Iniotaki $^{c}$ Petros P. Sfikakis $^{b}$ \\ Costas Siamopoulos $^{\text {d John Boletis }}{ }^{\text {a }}$ \\ ${ }^{a}$ Nephrology and Transplantation Center, Laiko Hospital, b Department of Internal Medicine, \\ University of Athens, and ' Histocompatibility Center, Gennimatas Hospital, Athens, and \\ ${ }^{\mathrm{d}}$ Department of Nephrology, University of Ioannina, Ioannina, Greece
}

\section{Key Words}

Idiopathic membranous glomerulopathy $\cdot$ Rituximab $\cdot$ B lymphocytes $\cdot$ B cell depletion

\begin{abstract}
Aims: To assess the long-term therapeutic benefit of temporary depletion of B lymphocytes in patients with idiopathic membranous glomerulopathy (MGN) and search for potential predictors of response. Patients and Methods: The patients included had been diagnosed with biopsy-proven MGN in the absence of secondary causes. Estimated glomerular filtration rate should be above $30 \mathrm{ml} / \mathrm{min} / 1.73 \mathrm{~m}^{2}$ and 24-hour proteinuria $3 \mathrm{~g} /$ day or more. Patients who had been treated with cyclosporine or cytotoxic agents the year prior to study entry were excluded. Depletion of $B$ cells was achieved with rituximab, which was administered intravenously for 4 consecutive weeks. Partial remission was defined as a $>50 \%$ decrease in proteinuria with absolute proteinuria $<3 \mathrm{~g} /$ day, while complete remission was defined as a $>50 \%$ decrease in proteinuria and an absolute protein excretion $<0.3 \mathrm{~g} /$ day. Results: Twelve patients were studied ( $4 \mathrm{fe}-$ males/8 males) with a mean age of 51.3 years. No major adverse effects were observed. During a median follow-up time of 48 months, 11/12 (91.6\%) patients achieved remission [7/12 (58.3\%) complete remission and 4/12 (33.3\%) partial remission], while 1 patient did not respond to therapy. Twelve months after therapy, $68.8 \%(p=0.003)$ of cases had achieved partial and $28.4 \%$ complete remission. Measurements of lymphocyte subpopulations did not reveal any changes
\end{abstract}

The results presented in this paper have not been published previously in whole or part, except in abstract format.

Sophia Lionaki, MD

Nephrology and Transplantation Center

Laiko Hospital

GR-11527 Athens (Greece)

E-Mail sofia.lionaki@gmail.com 
except for the B cell depletion. B cell infiltrates captured per $\mathrm{mm}^{3}$ of renal tissue in the diagnostic biopsy did not correlate with subsequent response. Conclusion: Depletion of B cells in idiopathic MGN was well tolerated and resulted in significant and long-lasting response rates in a series of 12 patients.

Copyright $\odot 2013$ S. Karger AG, Basel

\section{Introduction}

Treatment of idiopathic membranous glomerulopathy (MGN) has always been a challenge for practicing nephrologists since it is the most frequent histopathological finding among nephrotic adults $[1,2]$, with $40 \%$ of them reaching end-stage renal disease $[2,3]$. As the actual activity of the disease in a given patient is not known, treatment efficacy is not guaranteed and there may be cumulative toxicity from the drugs used in the treatment. Experimental models, which faithfully duplicate MGN, demonstrate deposition of immunoglobulins along with components of the complement system on the epithelial side of the glomerular basement membrane to be the primary mechanism of disease [2]. If B lymphocytes contribute substantially to MGN $[4,5]$ pathogenesis, then interventions targeting them should maximize the therapeutic benefit and minimize side effects. Rituximab, a chimeric monoclonal antibody, has been shown capable of suppressing B cells selectively, and not shrink the lymphocyte pool in total $[3,6,7]$. Promising results with this agent have been reported in several autoimmune disorders $[7,8]$, including MGN $[3,6]$, opening a new door to immunomodulation. However, several questions arise with respect to the duration of the presumed therapeutic effect, its precise mechanism of functioning and the impact, if any, on the Tlymphocyte pool.

This study explores the long-term clinical impact of B cell depletion in idiopathic MGN, and searches for subsequent phenotypic alterations of lymphocytic subpopulations in the periphery and $\mathrm{B}$ cell infiltrates in renal tissue.

\section{Methods}

\section{Selection of Patients}

Patients were eligible to participate if they fulfilled the following inclusion criteria: (a) age older than 18 years; (b) biopsy-proven MGN diagnosed within the previous 2 years; (c) proteinuria of at least $3 \mathrm{~g} / \mathrm{day}$; (d) minimum clearance of creatinine of $30 \mathrm{ml} / \mathrm{min}$, calculated by the Cockcroft-Gault formula, and (e) informed consent signed by the patient.

Patients were excluded if they tested positive for hepatitis B or C virus and human immunodeficiency virus or had any other acute or chronic active infection. In addition, women with MGN who were pregnant or in the nursing phase as well as patients with a history of neurological or hematological disorders were excluded. Patients with any exposure to cytotoxic agents, (chlorambucil or cyclophosphamide) within 6 months prior to consideration for entry and/or use of cyclosporine or steroids within 3 months before were excluded.

\section{Definitions}

Partial remission was defined as a decrease in proteinuria of $>50 \%$ with absolute proteinuria of $<3 \mathrm{~g} /$ day, while complete remission was defined as an absolute protein excretion of $<0.3 \mathrm{~g} /$ day. Response to therapy was defined as a reduction in proteinuria allowing any patient to achieve partial or complete remission sustained for a minimum of 6 months. Relapse was defined as an increase in 24-hour urine protein excretion of $>50 \%$. 


\section{Study Protocol}

Each patient received 4 weekly intravenous pulses of rituximab $\left(375 \mathrm{mg} / \mathrm{m}^{2}\right.$ of body surface). The maximum dose should not exceed $700 \mathrm{mg}$ each time. Treatment was preceded by a course of hydrocortisone $(500 \mathrm{mg}$ ) and an anti-histamine agent.

\section{Concomitant Therapy}

Nonsteroid anti-inflammatory agents were not allowed. All patients had been treated with angiotensin-converting enzyme inhibitors and/or angiotensin receptor blockers for a minimum of 6 months before entry. In addition, warfarin, heparin and diuretics were allowed by clinical indication; however, steroids were not given during the study period.

\section{Evaluation at Entry}

Baseline evaluations included physical examination as well as body weight and blood pressure measurements, in addition to 24 -hour protein excretion, which was captured by the mean value of 3 consecutive urine collections, serum creatinine and estimated glomerular filtration rate (eGFR) measurements, and counts of erythrocytes, white blood cell counts, platelets, lipid profile, albumin and lymphocytic subpopulations.

\section{Histopathological Assessment}

Renal biopsy specimens were processed for light-microscopy immunofluorescence analysis using standard techniques (hematoxylin and eosin, Masson's trichrome, periodic acidSchiff and silver stain). Histological changes were evaluated and assigned a score or a numerical value by a renal pathologist according to semi quantitative or quantitative criteria. Glomerular changes and the percentage of glomeruli with global sclerosis or segmental sclerosis over the total number of glomerular profiles were assessed. The increase in the mesangial matrix was scored as follows: $0=$ absent; $1=$ mild $(<25 \%) ; 2=$ moderate $(26-50 \%)$, and $3=$ severe $(>50 \%)$. The overall severity of glomerular changes was assigned a score as follows: $0=$ mild increase in the mesangial matrix; $1=$ moderate or severe increase in the mesangial matrix; 2 = presence of segmental glomerulosclerosis, and 3 = association of segmental glomerulosclerosis and an at least moderate increase in the mesangial matrix. Tubulointerstitial changes were scored as follows: $0=$ tubular atrophy absent; $1=$ tubular atrophy in up to $25 \%$ of the area of cortical tubules; $2=$ tubular atrophy involving $26-50 \%$ of the cortical area, and $3=$ tubular atrophy in $>50 \%$ of the cortical area. The severity of interstitial fibrosis was scored as follows: $0=$ absent; $1=$ interstitial fibrosis in up to $25 \%$ of the cortical area; $2=$ interstitial fibrosis in $26-50 \%$ of the cortical area, and $3=$ interstitial fibrosis in $>50 \%$ of the cortical area. The severity of interstitial inflammation was scored as follows: $0=$ absent; $1=$ up to $25 \%$ of the parenchyma inflamed; $2=26-50 \%$ of the parenchyma inflamed, and $3=$ $>50 \%$ of the parenchyma inflamed. The overall severity of tubulointerstitial involvement was quantified as the sum of the average score values of tubular atrophy, interstitial fibrosis and interstitial inflammation.

The thickening of the vascular wall, taken as a marker of sclerosing changes and hyalinosis of arteries and arterioles, was quantified with the following vascular scores: $0=$ absent; $1=$ mild (increase in thickness to a degree that is less than the diameter of the lumen); $2=$ moderate (increase in thickness equal or slightly greater to the diameter of the lumen), and $3=$ severe (wall thickness far exceeding the diameter of the lumen). The glomerular parietal diffuse C3 staining was assigned an intensity score that ranged from 1 (mild) to 3 (strong). The stage of the disease was graded from 1-4 according to the criteria of Ehrenreich and Churg (Jennette 2007). 
Computer-assisted morphometry was performed to evaluate $\mathrm{CD}_{45+}$ and $\mathrm{CD}_{20+}$ cells. Images were captured by a microscope-mounted high-resolution digital camera with a video output. Interstitial $\mathrm{CD}_{45+}$ and $\mathrm{CD}_{20+}$ cells were counted as number of positive cells $/ \mathrm{mm}^{2}$.

\section{Clinical Parameters during Follow-Up}

Patients were followed on a monthly basis after cessation of therapy (for a total of 12 months if at all possible) with physical examinations and labs, including a full biochemical profile, hematological indices, urine analysis, 24-hour urine protein excretion and blood lymphocyte subpopulations, namely B lymphocytes $\left(\mathrm{CD}_{20}\right.$ or $\mathrm{CD}_{19} \mathrm{~B}$ cells), T lymphocytes $\left(\mathrm{CD}_{3}\right)$, T helper cells $\left(\mathrm{CD}_{4}\right)$, cytotoxic T cells $\left(\mathrm{CD}_{8}\right)$, natural killer cells $\left(\mathrm{CD}_{3-16.56+}\right)$ and $\mathrm{CD}_{4} /$ $\mathrm{CD}_{8}$ ratios. We also measured the expression of $\mathrm{CD}_{69}$ and $\mathrm{CD}_{154}$ molecules. GFR was estimated by the Cockcroft-Gault formula at each visit.

\section{Statistical Methods}

The patients' characteristics were described using frequency tables, mean and standard deviation or median and 25th and 75th percentiles, as appropriate. Levels of urinary protein excretion and lymphocyte subpopulations at follow-up were compared to the baseline levels using the Wilcoxon matched-pairs signed-ranks test. The proportion of patients achieving partial and complete response over time was estimated using Kaplan-Meier analysis. The Cox proportional hazards model was used to assess the effect of clinical, laboratory and histological characteristics on the time of complete response.

\section{Results}

\section{Patient Characteristics at Entry}

Twelve patients were included with a mean age of $51.3 \pm 13.9$ years (min-max: 19-69). There were 8 men and 4 women. The median (25th, 75th) follow-up time was 39 months (15, 46; min-max: 9-62). Patient recruitment started in 2003. All participants had received full treatment with ACEI for at least 6 months with no improvement. Four of them had also been treated with immunosuppressants (cyclosporine, Ponticelli protocol and mycophenolate mofetil) with no response. The mean systolic blood pressure (SBP) was $122.2 \pm 11.5 \mathrm{~mm} \mathrm{Hg}$ and the mean diastolic blood pressure (DBP) $78.2 \pm 7.2 \mathrm{~mm} \mathrm{Hg}$. The median 24-hour urine protein excretion was $6.7 \mathrm{~g} /$ day $(3.8,10.4)$. The mean serum creatinine was $1.5 \pm 0.6 \mathrm{mg} / \mathrm{dl}$, corresponding to a mean eGFR of $77.6 \pm 38.2 \mathrm{ml} / \mathrm{min}$, and the mean serum albumin was $3.2 \pm 0.5 \mathrm{~g} / \mathrm{dl}$. Mean serum cholesterol was $276.7 \pm 55 \mathrm{mg} / \mathrm{dl}$ and mean serum triglycerides $210 \pm 760 \mathrm{mg} / \mathrm{dl}$ (table 1$)$.

\section{Histopathological Assessment at Diagnosis}

There was 1 (8.3\%) patient with MGN stage I, 3 (25\%) with MGN stage I/II, 7 (58.3\%) with MGN stage II and 1 (8.3\%) with MGN stage III. Specific histopathological parameters were as follows:

- Global glomerular sclerosis: a score of 0 was found in $4(36.4 \%)$ patients, a score of 1 in $6(54.6 \%)$ patients, and a score of 3 in $1(9.1 \%)$ patient. Segmental glomerular sclerosis was absent (score $=0)$ in all $(100 \%)$ patients.

- Overall glomerular damage: a score of 0 was shown in $6(54.5 \%)$ patients, a score of 1 in $4(36.4 \%)$ patients, a score of 2 in no patient and a score of 3 in $1(9.1 \%)$ patient.

- Tubular changes: a score of 0 was found in $4(36.4 \%)$ patients, a score of 1 in $5(45.5 \%)$ patients and a score of 2 in $1(9.1 \%)$ patient. 
Lionaki et al.: Depletion of B Lymphocytes in Idiop

Table 1. Characteristics of patients during the follow-up time

\begin{tabular}{|c|c|c|c|c|c|c|c|c|}
\hline \multirow[t]{2}{*}{ Characteristics } & \multicolumn{8}{|c|}{ Months after rituximab therapy } \\
\hline & $0(\mathrm{n}=12)$ & $3(\mathrm{n}=12)$ & $6(\mathrm{n}=12)$ & $9(\mathrm{n}=11)$ & $12(\mathrm{n}=11)$ & $15(\mathrm{n}=10)$ & $24(\mathrm{n}=10)$ & $42(n=10)$ \\
\hline Body weight, kg & $83.1 \pm 13.9$ & $82.1 \pm 12.1$ & $82.3 \pm 12.6$ & $83.5 \pm 10.3$ & $80.4 \pm 12.2$ & $78.3 \pm 12.5$ & $81.6 \pm 10.9$ & $82.5 \pm 11.8$ \\
\hline $\mathrm{SBP}, \mathrm{mm} \mathrm{Hg}$ & $122.2 \pm 11.5$ & $126.9 \pm 15.4$ & $123.6 \pm 9.4$ & $117.5 \pm 10.0$ & $126.5 \pm 16.4$ & $111.6 \pm 9.5$ & $118.2 \pm 11.1$ & $119.4 \pm 20.0$ \\
\hline $\mathrm{DBP}, \mathrm{mm} \mathrm{Hg}$ & $78.3 \pm 7.2$ & $78.5 \pm 8.4$ & $73.3 \pm 4.9$ & $72.5 \pm 5.7$ & $76.4 \pm 9.2$ & $75.2 \pm 6.7$ & $73.2 \pm 6.3$ & $76.0 \pm 13.3$ \\
\hline Serum creatinine, mmol/l & $132 \pm 53.04$ & $132 \pm 61.88$ & $123.7 \pm 53.04$ & $114.9 \pm 44.2$ & $123.7 \pm 53.04$ & $123.7 \pm 61.88$ & $123.7 \pm 53.04$ & $132 \pm 70.72$ \\
\hline Serum albumin, g/dl & $3.2 \pm 0.5$ & $3.4 \pm 0.8$ & $3.7 \pm 0.6$ & $3.8 \pm 0.7$ & $4.0 \pm 0.5^{*}$ & $4.2 \pm 0.3^{*}$ & $4.1 \pm 0.5^{*}$ & $4.4 \pm 0.3^{*}$ \\
\hline eGFR, $\mathrm{ml} / \mathrm{min} / 1.73 \mathrm{~m}^{2}$ & $77.6 \pm 38.2$ & $76.3 \pm 36.9$ & $79.3 \pm 33.2$ & $79.7 \pm 32.5$ & $79.1 \pm 38.2$ & $79.7 \pm 39.3$ & $80.4 \pm 41.8$ & $80.9 \pm 41.1$ \\
\hline Serum cholesterol, mmol/l & $7.17 \pm 1.42$ & $6.69 \pm 1.20$ & $6.7 \pm 1.5)$ & $6.11 \pm 1.34$ & $5.63 \pm 0.95^{*}$ & $5.72 \pm 1.27$ & $5.72 \pm 1.32$ & $5.92 \pm 1.24$ \\
\hline Serum triglycerides, $\mathrm{mmol} / \mathrm{l}$ & $2.37 \pm 0.86$ & $2.33 \pm 1.39$ & $1.97 \pm 0.68$ & $2.03 \pm 0.80$ & $1.95 \pm 1.31$ & $1.73 \pm 0.83$ & $1.57 \pm 0.68$ & $1.84 \pm 0.78$ \\
\hline
\end{tabular}

Values are means \pm SD at entry and after treatment with rituximab.

* Statistical significance at the $5 \%$ level with Bonferroni adjustment, compared to values at entry (month 0).

- Interstitial fibrosis: a score of 0 was found in 5 (45.5\%) patients, a score of 1 in 5 (45.5\%) patients, a score of 2 in no patient and a score of 3 in 1 (9.1\%) case.

- Interstitial inflammation: 4 patients (36.4\%) had a score of 0 and 7 patients $(63.6 \%)$ had a score of 1 .

- Measurement of CD20 in kidney biopsy specimens: the mean number of CD45+ was $153.58 \pm 84.71$ cells per $\mathrm{mm}^{2}$ of renal tissue, and the mean number of CD20 was 39.33 \pm 42.09 cells per $\mathrm{mm}^{2}$ of renal tissue. No association was observed between the number of infiltrated CD45+ and CD20 cells in the renal tissue at the time of MGN diagnosis with subsequent response to therapy with rituximab.

\section{Outcomes}

Safety and Tolerability

Treatment with rituximab was well tolerated in all patients. Serious adverse events did not occur. Serum creatinine and eGFR were not significantly altered in serial measurements during the observation period. At end of follow-up, 7 (58.3\%) patients had achieved complete remission and $4(33.3 \%)$ had achieved partial remission, while $1(8.3 \%)$ patient had no response. Measuring the 24-hour urinary protein excretion every month in all patients revealed that in those cases who achieved complete remission, this was preceded by a phase of partial remission (table 2). A significant reduction in the 24-hour urinary excretion was observed 9 months after treatment $(\mathrm{p}=0.033)$. At that point, $58.3 \%$ of the cases had achieved partial remission (median 24-hour protein excretion $1.3 \mathrm{~g}$ ) and none complete remission. Twelve months after therapy, the median 24 -hour protein excretion was further significantly reduced to $0.8 \mathrm{~g}(\mathrm{p}=0.003)$. Then, $68.8 \%$ of the patients had achieved partial remission and $18.2 \%$ complete remission. At 15 months after therapy, the median 24-hour proteinuria was $1.1 \mathrm{~g}(\mathrm{p}=0.005)$, and $89.6 \%$ of the patients were in partial remission and $27.3 \%$ in complete remission. After this, 3 additional patients achieved complete remission 24, 30 and 42 months after therapy, respectively (they had been in partial remission 2 months after therapy initiation). All comparisons refer to the baseline 24 -hour proteinuria (table 2). The median time interval from rituximab administration to partial remission was 6 months $(\mathrm{n}=11$; min-max: 3-15) (fig. 1-3).

Serum cholesterol was shown to be significantly reduced $(p<0.05) 12$ months after therapy, as were serum triglycerides 6 months after therapy $(\mathrm{p}<0.001)$ and afterwards (table 1). 
Table 2. Measurements of 24-hour proteinuria during the follow-up time

\begin{tabular}{llllll}
\hline $\begin{array}{l}\text { Months } \\
\text { after } \\
\text { therapy }\end{array}$ & $\begin{array}{l}\text { Patients } \\
\mathrm{n}\end{array}$ & $\begin{array}{l}\text { Median 24-hour protein- } \\
\text { uria (25th, 75th), /day }\end{array}$ & $\begin{array}{l}\text { p value, vs. } \\
\text { month } 0\end{array}$ & $\begin{array}{l}\text { Response rate } \\
\begin{array}{l}\text { partial } \\
\text { remission, \% }\end{array}\end{array}$ & $\begin{array}{l}\text { complete } \\
\text { remission, \% }\end{array}$ \\
\hline 0 & 12 & $6.7(3.8,10.4)$ & NA & NA & NA \\
3 & 12 & $4.7(1.7,8.2)$ & 0.084 & 33.3 & 0 \\
6 & 9 & $2.6(1.8,6.7)$ & 0.260 & 50.0 & 0 \\
9 & 11 & $1.3(0.5,5.2)$ & 0.033 & 58.3 & 0 \\
12 & 11 & $0.8(0.4,3.5)$ & $0.003^{*}$ & 68.8 & 28.4 \\
15 & 10 & $1.1(0.4,1.6)$ & $0.005^{*}$ & 89.6 & 27.3 \\
24 & 10 & $0.8(0.2,1.9)$ & $0.005^{*}$ & 89.6 & 45.5 \\
42 & 10 & $0.2(0.1,0.5)$ & $0.005^{*}$ & 100.0 & 72.7 \\
\hline
\end{tabular}

* Statistically significant difference at the 5\% level using Bonferroni adjustment.

Fig. 1. a Rate of partial remission over time. b Rate of complete remission over time.
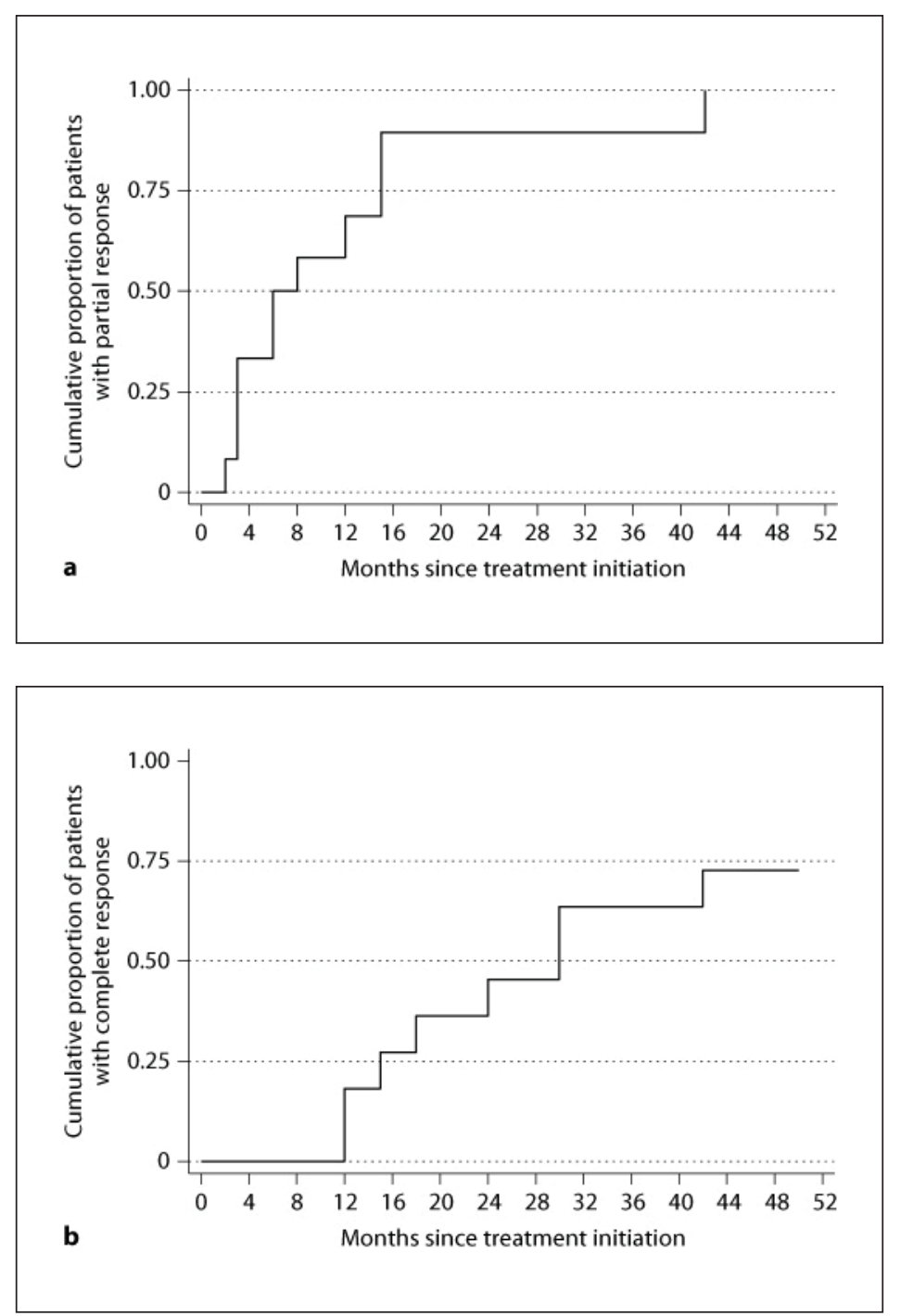
Table 3. Predictors of complete response: evaluation of clinical and laboratory parameters

\begin{tabular}{lll}
\hline Characteristics & Hazard ratio $(95 \% \mathrm{CI})$ & p value \\
\hline Age (per decade) & $0.74(0.42,1.33)$ & 0.322 \\
Gender (female vs. male) & $2.56(0.62,10.6)$ & 0.193 \\
MGN stage (II, III vs. I, I/II) & $0.74(0.43,1.26)$ & 0.268 \\
Body weight (per 5-kg increase) & $0.85(0.58,1.24)$ & 0.393 \\
DBP & $0.99(0.90,1.09)$ & 0.851 \\
SBP & $0.99(0.92,1.06)$ & 0.733 \\
Serum albumin (per 0.5-g/dl increase) & $2.70(1.04,6.99)$ & 0.040 \\
Serum creatinine (per 44.2-mmol/l increase) & $0.34(10.608,85.75)$ & 0.043 \\
24-hour proteinuria (per 1-g/24 h increase) & $0.73(0.53,1.00)$ & 0.047 \\
Nephrotic vs. non-nephrotic 24-hour & & \\
$\quad$ proteinuria (<3.5 vs. $\geq 3.5$ g/24 h) & $14.3(1.41,145.6)$ & 0.024 \\
eGFR (per 10-unit increase) & $1.21(0.99,1.49)$ & 0.064 \\
Serum cholesterol (mmol/l) & $1.01(0.025,0.026)$ & 0.482 \\
Serum triglycerides (mmol/l) & $1.00(0.0111,0.0114)$ & 0.560 \\
\hline
\end{tabular}

\section{Predictors of Response to Therapy}

We analyzed clinical, laboratory and histopathological parameters that might predict response to therapy. Serum albumin was associated with response to treatment, i.e., patients with a higher serum albumin at entry (per $0.5 \mathrm{~g} / \mathrm{dl}$ of increase) were 2.7 times (95\% CI: $1.04-$ $6.99, \mathrm{p}=0.04)$ more likely to respond to therapy $(\mathrm{p}=0.04)$. In addition, patients with nephrotic range proteinuria were shown 14.3 times (95\% CI: $1.41-145.6, \mathrm{p}=0.024$ ) less likely to respond to therapy with rituximab (table 3 ). None of the remaining parameters, including the number of $\mathrm{B}$ cells per $\mathrm{mm}^{3}$ of renal tissue, was associated with either partial or complete remission.

\section{Lymphocyte Subpopulations}

B lymphocytes $\left(\mathrm{CD}_{20}\right)$ were depleted in all patients within a mean time of 1 month after rituximab administration. The mean duration of $\mathrm{B}$ cell $\left(\mathrm{CD}_{20}\right)$ depletion was 6 months (minmax: 5-10). During recovery, the absolute numbers of $B$ cells remained significantly different compared with the numbers of B cells at entry $(\mathrm{p}=0.003)$, and remained altered until the end of the observation period $(\mathrm{p}=0.023)$. A trend towards increased $\mathrm{CD}_{425}$ was recorded at the final measurement.

We found no significant changes in the total number of leucocytes or lymphocyte subpopulations (compared with the corresponding numbers at entry) at the time of B cell depletion and B cell recovery as well as at the end of observation, i.e., 9-12 months after therapy.

\section{Discussion}

This study reports extended clinical outcomes and measurements of patients with MGN after treatment with rituximab. We observed significant response rates, with 11/12 (33.3\%) of participants achieving partial remission and $58.3 \%$ complete remission. The median time to partial remission was 6 months and to complete remission 24 months. However, partial remission was followed by complete remission in all cases, resulting in a response rate of 91.6\% during a median follow-up time of 48 months. Rituximab for MGN was first introduced by Remuzzi et al. [6] using the same dosage scheme. Twenty-four-hour protein excre- 
Fig. 2. Alteration of 24-hour urinary protein excretion per patient over time.
Fig. 3. Median (25th, 75th) 24hour urinary protein excretion in 12 patients over time.
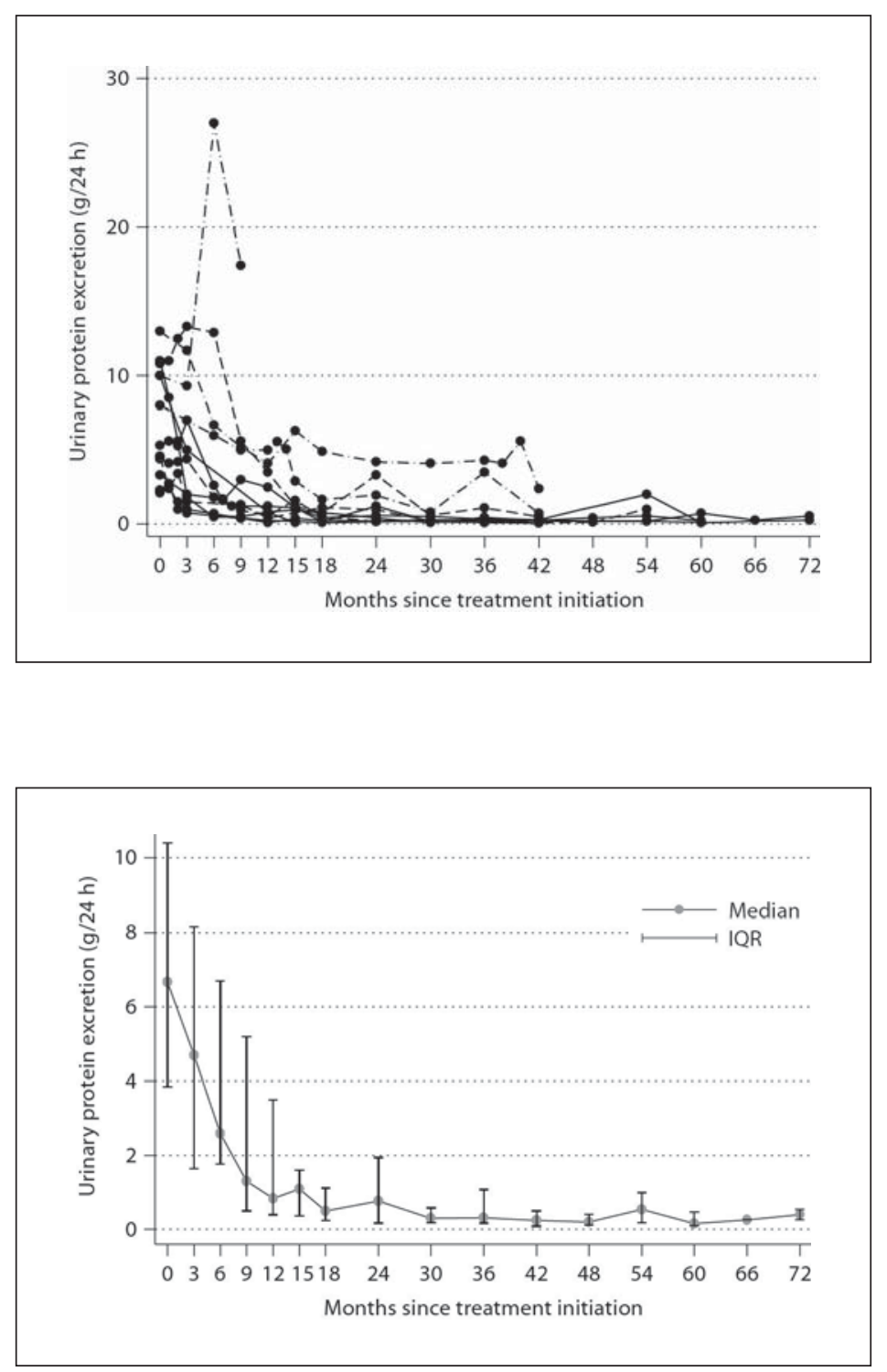

tion was decreased from a mean of $8.6 \mathrm{~g} /$ day to $3.8 \mathrm{~g} /$ day during a 20 -week follow-up time in that study [6], while evaluation of those patients after a 12-month observation period revealed sustained remission [3]. We observed higher remission rates, but several differences can explain our results. First, all patients who achieved complete remission (fig. 2, 3) did so in a median time of 24 months, and all did so through a phase of partial remission. This finding not only addresses once again the importance of partial remission [9] during the course of MGN, but also magnifies the potential of a new type of path physiologic action. Considering this, we speculate that improvement and finally normalization of protein excretion might be accompanied by constant and gradual glomerular changes towards normal structure. Since no subsequent histological data are available at the moment on these patients, we cannot know the direction of improvement, i.e., absorption of immune deposits or other types of transformation. Yet, the main argument allowing this hypothesis is the fact that no modification of the concomitant therapy was done during the study period. If depletion of $\mathrm{B}$ cells acts by restoring the normal glomerular basement micro-anatomy, this pos- 
sibly occurs by interrupting the pathogenetic pathway, which leads to podocyte damage. However, the potential of repairing immunological abnormalities and reinstate the function of the host immune system remains to be proved.

Likewise, Ruggenenti et al. [10] described specific morphofunctional changes in remitted MGN patients, evident within a median time of 21 months after rituximab therapy. However, unlike ours, their findings were confirmed by tissue reevaluations, i.e., reabsorption of subepithelial deposits shown in electronic microscopy [10]. This suggestion coincides with the functional action of cyclosporine, which occurs soon after initiation, resulting in remission rates as high as $70 \%$ soon after therapy initiation. However, considerable relapse rates following discontinuation of cyclosporine have been reported [11].

Scoring histopathological indexes of the diagnostic biopsies showed that our patients had no chronic lesions. It is possible that rituximab is more advantageous when given in earlier stages of MGN, when chronicity is not present. Correlations of histological and clinical characteristics at the time of initial treatment, encourage this hypothesis [12]. Besides, we found that patients with higher serum albumin and higher GFR were more likely to respond to therapy with rituximab. Accordingly, patients with lower protein excretion, as reflected in the 24-hour collection, were more likely to achieve remission. All taken together, this points to the significance of prompt discovery of the disease, at it is more likely to be reversible at an early stage. However, Fervenza et al. [13] studied 15 severely nephrotic patients treated with rituximab and observed full remission in 2 and partial remission in 6 cases, while proteinuria was significantly decreased at 12 months. The authors concluded that rituximab is effective in some cases with idiopathic MGN [13]. Nevertheless, the allocation of a given patient by risk progression is the key step in planning MGN therapy [14] and, probably, patients with medium or low risk indexes of damage by histology are more likely to respond to rituximab.

We found no association between the number of infiltrated $\mathrm{CD}_{45}$ and $\mathrm{CD}_{20}$ cells in renal tissue at MGN diagnosis and subsequent response to rituximab, a finding which is in agreement with earlier studies $[13,22]$. The contribution of B cells in renal inflammation has always been considered a potential factor [15], but there is also substantial uncertainty regarding the ectopic formation of lymphoid follicle-like aggregates at sites of chronic inflammation $[16,17]$. Although the number of $B$ cells in renal tissue has been described to be low [18-21], a prominent accumulation of B cells was reported in MGN [5]. B cell infiltrates are highly present in renal allograft rejection, aggregates or scattered interstitial patterns [23].

All patients in our study exhibited depletion of B cells for about 6 months. Lymphocyte subpopulations were not altered significantly during the follow-up time, with the exception of $\mathrm{CD}_{20}$ cells numbers. Most investigators $[3,6,12]$ focus in the follow-up of rituximab therapy on measuring circulating B cells as we did in the current study. Whether this parameter is the most appropriate one to reflect the impact of such therapy on the immune system and on tertiary lymphoid organs is of question. For instance, it has been shown that some transplant patients with acute rejection fail to respond to rituximab despite depletion of B cells in the periphery [24]. An inflammatory microenvironment provides paracrine survival signals to B cells in tertiary lymphoid organs, allowing them to escape rituximab-induced apoptosis, and thereby thwarting therapeutic efficiency [25-27]. Besides, studies on fully functional ectopic lymphoid tissues suggest that the local humoral immune response participates in such pathological processes [28]. Similar studies on rheumatoid arthritis demonstrated that, unlike those in circulation, synovial B cells may be decreased but not eliminated by rituximab, while there is a correlation between synovial B cell depletion and clinical response to this agent [29]. However, as recently shown, the primary form of MGN is associated with the occurrence of specific antibodies, which are directed against the M-type of the phospholipase A2 receptor and are found in the great majority of patients [30], and 
thus inhibiting humoral response and clearance of them may consequently be proven of great importance.

Limitations of our study include the small number of participants and the lack of a control group to assess spontaneously remitted subjects. Also, the 4-week regimen of rituximab, which was used in this study, is nowadays of question since the titrated option might be of equal results [23]. However, patient recruitment started in 2003, when data regarding rituximab in MGN was limited. Indeed, protocol biopsies might be of interest in these patients to assess correlations between response and morphological alterations by electronical microscopy.

In conclusion, temporary depletion of B lymphocytes was shown efficacious in reducing proteinuria in patients with mild tissue damage from MGN. $\mathrm{CD}_{20}$ cell numbers were exclusively changed after therapy, while B cell infiltrates in renal tissue at study begin could not predict subsequent response. Remission was achieved long after administration of treatment, allowing us to assume blockage of the immunological insult and gradual remodelling of the glomerular filter [32]. Although these results are not efficient to make any recommendations on MGN treatment, we think that such findings point to the need for future research to investigate the precise mechanism of rituximab on the immune repertoire of patients with MGN.

\section{References}

1 Cattran DC: Membranous nephropathy: quo vadis? Kidney Int 2002;61:349-350.

-2 Kshirsagar AV, Nachman PH, Falk RJ: Alternative therapies and future intervention for treatment of membranous nephropathy. Semin Nephrol 2003;23:362-372.

-3 Ruggenenti P, Chiurchiu C, Brusegan V, et al: Rituximab in idiopathic membranous nephropathy: a one-year prospective study. J Am Soc Nephrol 2003;14:1851-1857.

-4 Kerjaschki D, Neale TJ: Molecular mechanisms of glomerular injury in rat experimental membranous nephropathy (Heymann nephritis). J Am Soc Nephrol 1996;7:2518-2526.

-5 Cohen CD, Calvaresi N, Armelloni S, et al: CD20-positive infiltrates in human membranous glomerulonephritis. J Nephrol 2005;18:328-333.

6 Remuzzi G, Chiurchiu C, Abbate M, et al: Rituximab for idiopathic membranous nephropathy. Lancet 2002;360:923-924.

-7 Sfikakis PP, Boletis JN, Lionaki S, et al: Remission of proliferative lupus nephritis following B cell depletion therapy is preceded by down-regulation of the T cell costimulatory molecule CD40 ligand: an open-label trial. Arthritis Rheum 2005;52:501-513.

8 Edwards JC, Szczepanski L, Szechinski J, et al: Efficacy of B-cell-targeted therapy with rituximab in patients with rheumatoid arthritis. N Engl J Med 2004;350:2572-2581.

-9 Troyanov S, Wall CA, Miller JA, Scholey JW, Cattran DC;: Toronto Glomerulonephritis Registry Group: Idiopathic membranous nephropathy: definition and relevance of a partial remission. Kidney Int 2004;66:1199-1205.

10 Ruggenenti P, Cravedi P, Sghirlanzoni MC, et al: Effects of rituximab on morphofunctional abnormalities of membranous glomerulopathy. Clin J Am Soc Nephrol 2008;3:1652-1659.

-11 Cattran DC, Appel G, Hebert L, Hunsicker LG, Pohl MA, Hoy WE, Maxwell DR, Kunis CL, North American Nephrotic Syndrome Study Group: Cyclosporine in patients with steroid resistant membranous nephropathy: a randomized trial. Kidney Int 2001;59:1484-1490.

-12 Ruggenenti P, Chiurchiu C, Abbate M, et al: Rituximab for idiopathic membranous nephropathy: who can benefit? Clin J Am Soc Nephrol 2006;1:738-748.

-13 Fervenza FC, Cosio FG, Erickson SB, et al: Rituximab treatment of idiopathic membranous nephropathy. Kidney Int 2008;73:117-125.

14 Cattran D: Management of membranous nephropathy: when and what for treatment. J Am Soc Nephrol 2005;16:1188-1194. 
Lionaki et al.: Depletion of B Lymphocytes in Idiopathic Membranous Glomerulopathy:

Results from Patients with Extended Follow-Up

15 Heller F, Lindenmeyer MT, Cohen CD, et al: The contribution of B cells to renal interstitial inflammation. Am J Pathol 2007;170:457-468.

16 Martin F, Chan AC: B cell immunobiology in disease: evolving concepts from the clinic. Annu Rev Immunol 2006;24:467-496.

-17 Kerjaschki D, Regele HM, Moosberger I, et al: Lymphatic neoangiogenesis in human kidney transplants is associated with immunologically active lymphocytic infiltrates. J Am Soc Nephrol 2004;15: 827-829.

18 Cybulsky AV, Quigg RJ, Salant DJ: Experimental membranous nephropathy redux. Am J Physiol Renal Physiol 2005;289:F660-F671.

-19 Hooke DH, Gee DC, Atkins RC: Leukocyte analysis using monoclonal antibodies in human glomerulonephritis. Kidney Int 1987;31:964-972.

20 D’Agati VD, Appel GB, Estes D, Knowles DM 2nd, Pirani CL: Monoclonal antibody identification of infiltrating mononuclear leukocytes in lupus nephritis. Kidney Int 1986;30:573-581.

-21 Husby G, Tung KS, Williams RC Jr: Characterization of renal tissue lymphocytes in patients with interstitial nephritis. Am J Med 1981;70:31-38.

-22 Boucher A, Droz D, Adafer E, Noël LH: Characterization of mononuclear cell subsets in renal cellular interstitial infiltrates. Kidney Int 1986;29:1043-1049.

-23 Ruggenenti P, Cravedi P, Remuzzi G: Latest treatment strategies for membranous nephropathy. Expert Opin Pharmacother 2007;8:3159-3171.

-24 Scheepstra C, Bemelman FJ, van der Loos C, et al: B cells in cluster or in a scattered pattern do not correlate with clinical outcome of renal allograft rejection. Transplantation 2008;86:772-778.

-25 Couser WG, Wagonfeld JB, Spargo BH, Lewis EJ: Glomerular deposition of tumor antigen in membranous nephropathy associated with colonic carcinoma. Am J Med 1974;57:962-970.

-26 Ronco P, Debiec H: Pathophysiological lessons from rare associations of immunological disorders. Pediatr Nephrol 2009;24:3-8.

-27 Thaunat O, Patey N, Gautreau C, Lechaton S, et al: B cell survival in intragraft tertiary lymphoid organs after rituximab therapy. Transplantation 2008;85:1648-1653.

-28 Aloisi F, Pujol-Borrell R: Lymphoid neogenesis in chronic inflammatory diseases. Nat Rev Immunol 2006;6:205-217.

-29 Kavanaugh A, Rosengren S, Lee SJ, Hammaker D, et al: Assessment of rituximab's immunomodulatory synovial effects (ARISE trial). 1: clinical and synovial biomarker results. Ann Rheum Dis 2008; 67:402-408.

-30 Beck LH Jr, Bonegio RG, Lambeau G, et al: M-type phospholipase A2 receptor as target antigen in idiopathic membranous nephropathy. N Engl J Med 2009;361:11-21.

-31 Cravedi P, Ruggenenti P, Sghirlanzoni MC, et al: Titrating rituximab to circulating B cells to optimize lymphocytolytic therapy in idiopathic membranous nephropathy. Clin J Am Soc Nephrol 2007;2: 932-937.

32 Ehrenreich T, Porush JG, Churg J, Garfinkel L, Glabman S, Goldstein MH, Grisham E, Yunis SL:

- Treatment of idiopathic membranous nephropathy. N Engl J Med 1976;295:741-746. 